\title{
Maternal Nicotine Exposure Induces Congenital Heart Defects in the Offspring of Mice
}

\author{
Elizabeth Greco ${ }^{1}$, Anish Engineer ${ }^{1}$, Xiangru Lu ${ }^{1}$, Douglas Jones ${ }^{1}$, and Qingping Feng ${ }^{1}$ \\ ${ }^{1}$ Western University Schulich School of Medicine and Dentistry
}

October 21, 2020

\begin{abstract}
Background and Purpose: Congenital heart defects (CHDs) are the most prevalent birth defect, and maternal cigarette smoking is a known risk factor. Nicotine replacement therapies are recommended to pregnant women who smoke to aid in smoking cessation, as this alternative is thought to be safer compared to cigarette smoking. However, these products contain nicotine, and the safety of nicotine on the developing heart is not well known. We examined the effects of maternal nicotine exposure (MNE) during pregnancy on fetal heart development in mice. Experimental Approach: C57BL/6 female mice were treated with nicotine at $1.5 \mathrm{mg} / \mathrm{kg} /$ day using subcutaneous osmotic pumps and bred with normal male mice. The effects of MNE on fetal hearts were analyzed. Key Results: MNE resulted in CHDs and hypoplastic coronary arteries in fetal mice at significant incidences of $43 \%$ and $31 \%$, respectively. CHDs included septal defects, atrioventricular septal defects, double outlet right ventricles, thickened aortic and pulmonary valves, isolated hypoplastic left ventricles, and ventricular hypertrophy. Moreover, MNE resulted in altered gene expression of key cardiogenic regulators and higher levels of oxidative stress in the embryonic hearts. Fetal heart epicardial epithelial-to-mesenchymal transition (EMT) was lower with MNE. Conclusions and Implications: MNE results in a higher incidence of congenital heart defects and coronary artery defects. These findings provide insight into the dangers of nicotine replacement therapy to fetuses during pregnancy.
\end{abstract}

\section{Hosted file}

Manucript - BJP 2020-10-20.pdf available at https://authorea.com/users/369234/articles/ 488158-maternal-nicotine-exposure-induces-congenital-heart-defects-in-the-offspring-ofmice

\section{Hosted file}

Manuscipt - Figures BJP 2020-10-20.pdf available at https://authorea.com/users/369234/ articles/488158-maternal-nicotine-exposure-induces-congenital-heart-defects-in-theoffspring-of-mice 